\title{
La indeterminación competencial y la potestad sancionadora de los entes locales como presupuesto fallido para la sustitución de las sanciones administrativas por trabajos en beneficio de la comunidad
}

\author{
Competence uncertainty and legal authority of the local entity \\ as an unsuccessful measurement to the replacement \\ of administrative sanctions by community services
}

Cristian Rodríguez Alonso cristian.rguez@hotmail.com

\begin{abstract}
RESUMEN
La promulgación de la Constitución Española de 1978 supuso no solo la culminación del proceso de transición democrática sino también la instauración de un nuevo modelo de estado integrado por diversos entes, todos ellos con personalidad jurídica y competencias propias, pero concurriendo su halo de poder sobre una misma base territorial. En el ámbito local supuso dotar de garantía constitucional a dichos entes pero dejando en manos del legislador estatal cuál es su campo concreto de actuación, es decir, cuál sería el alcance de sus competencias, ante el silencio de la Constitución. Esta regulación deja en manos del legislador estatal la concreción del alcance, límites y competencias de la actuación de los entes locales lo que implica que la actuación de los entes locales esté acotada por la regulación constitucional y estatal, y por ende, aunque desde un punto de vista de política social parezca que la sustitución de las sanciones administrativas por trabajos en beneficio de la comunidad beneficie al conjunto de los ciudadanos, admitir dicha posibilidad, con la regulación actual, supondría una quiebra de las garantías y principios constitucionales.
\end{abstract}

\section{Palabras clave}

Garantía constitucional, trabajos en beneficio de la comunidad, ley de bases, competencia, ente local, inconstitucional.

\begin{abstract}
The enactment of the 1978 Spanish Constitution meant not only the culmination of the democratic transition process, but also the instauration of a new state model built in diverse entities, each one of them with legal personality and competence on its own, that got together under the power of a common territorial base. In the local field, it provided those entities of constitutional guarantee, but left in the hands of the state legislator in which fields they could act; in other words, the scope of their competences in front of the silence of the Constitution. This regulation, then, allows the state legislator to specify the scope, limits, and competences of intervention of the local entities, thus implying that local actions are delimited by both the state and the constitutional regulation. Therefore, even though from the social politics' point of view it would sound as beneficial for the citizens to impose community services instead of administrative sanctions, saying so, from the current regulation, would meant a rupture of the constitutional principles and guarantees.
\end{abstract}

\section{Keywords}

Constitutional guarantee, community services, Bases Law, competence, local entities, unconstitutional. 
REALA. Nueva Época - N. ${ }^{\circ}$ 6, noviembre 2016 - ISSN: 1989-8975 - DOI: 10.24965/reala.v0i6.10390 - [Págs. 93-104]

La indeterminación competencial y la potestad sancionadora de los entes locales como presupuesto fallido para la sustitución de ...

Cristian Rodríguez Alonso

\begin{abstract}
SUMARIO
I. INTRODUCCIÓN. II. LA INDETERMINACIÓN LOCAL EN EL REPARTO DE COMPETENCIAS EN LA CONSTITUCIÓN DE 1978. III. LA POTESTAD SANCIONADORA DE LOS ENTES LOCALES COMO INTENTO DE FUNDAMENTACIÓN DE LA SUSTITUCIÓN DE SANCIONES ADMINISTRATIVAS EN EL ÁMBITO DE SUS COMPETENCIAS POR TRABAJOS EN BENEFICIO DE LA COMUNIDAD. IV. CONCLUSIÓN.
\end{abstract}

\title{
I. INTRODUCCIÓN
}

La promulgación de la Constitución en 1978 no solo supuso la consolidación de «un Estado social y democrático de Derecho» (artículo 1.1 Constitución) si no el establecimiento de un nuevo modelo de estado, a camino entre el estado federal y el regional, denominado estado autonómico, fruto de la imposibilidad de llegar a un consenso por los constituyentes ${ }^{1}$.

A diferencia de lo que ocurre en la mayor parte de estados europeos ${ }^{2}$, la falta de consenso en el modelo de estado supuso que no se concretase en el propio texto constitucional y su especificación fuese de construcción doctrinal, sustentada además por la aplicación práctica e interpretación que realiza el máximo intérprete de la Constitución.

Dicho nuevo modelo de estado se basó en la indisoluble unidad de la Nación, pero respetando la autonomía de los entes que la reciente descentralización del Estado les otorgó. Así lo expone Villacorta Mancebo al determinar que la estructuración del poder del Estado se basa en el principio de unidad, fundamento de la propia Constitución, y en los de autonomía y solidaridad. La Constitución parte de la unidad de la Nación española que se constituye en Estado social y democrático de Derecho, cuyos poderes emanan del pueblo español en el que reside la soberanía nacional. Esta unidad se traduce así en una organización -el Estado- para todo el territorio nacional. Pero los órganos generales del Estado no ejercen la totalidad del poder público, porque la Constitución prevé, con arreglo a una distribución vertical de poderes, la participación en el ejercicio del poder de entidades territoriales de distinto rango, tal como se expresa en el artículo 137 de la Constitución al decir que «el Estado se organiza territorialmente en municipios, en provincias y en las Comunidades Autónomas que se constituyan. Todas estas entidades gozan de autonomía para la gestión de sus respectivos intereses» ${ }^{3}$. Bajo esta indeterminación a la hora de proclamar el modelo de estado, la Constitución procedió a fijar las competencias de cada uno de los estratos o niveles territoriales de poder ${ }^{4}$ en los que se dividió el Estado. Haciéndolo de manera expresa para los niveles estatal y autonómico, pero dejando una notable imprecisión en cuanto a las competencias de las entidades locales, acuñando la terminología de los «respectivos intereses» como cláusula para la atribución competencial a estas entidades.

Esta notable indeterminación constitucional, respecto a las bases de actuación de las entidades locales ${ }^{5}$, ha generado una fuerte evolución doctrinal, normativa e interpretativa de los preceptos constitucionales referidos a las citadas entidades que han elaborado un entramado complejo de límites, no del todo preciso, y de indefinición a la hora de actuar dentro de un marco competencial concreto. Esto ha supuesto que la labor y la actividad de los entes locales se vea, en muchos casos, condicionada a las competencias y a la actua-

\footnotetext{
1 España es, en la actualidad, un país descentralizado que ha establecido la ordenación territorial del poder en torno a lo que se ha denominado Estado autonómico. Esta denominación es original del constitucionalismo español, pues no se encuentra con anterioridad en otra sede y es la consecuencia de la falta de consenso de los constituyentes sobre los modelos de estado federal y estado regional. AJA FERNÁNDEZ, E (1999). El Estado Autonómico. Federalismo y hechos diferenciales. Alianza. Madrid.

2 Cabe citar como ejemplos el artículo 20.1 de la Ley Fundamental para la República Federal de Alemania (Grundgesetz für die Bundesrepublik Deutschland) que define a Alemania como «un Estado Federal, democrático y social»; así como el artículo 1 de la Constitución de Bélgica (De Belgische Grondwet) que establece que «Bélgica es un Estado Federal compuesto de Comunidades y Regiones».

3 VILLACORTA MANCEBO, L (2001): «Sobre el principio estructural de autonomía en la Constitución española y su desarrollo», Cuadernos constitucionales de la Cátedra Fadrique Furió Ceriol. XXXVI-XXXVII: 49-88.

${ }^{4}$ Sentencia del Tribunal Constitucional 32/1981, de 28 de febrero: «la Constitución prefigura una distribución vertical del poder público entre entidades de distinto nivel que son fundamentalmente el Estado, titular de la soberanía; las Comunidades Autónomas, caracterizadas por su autonomía política, y las provincias y municipios, dotadas de autonomía administrativa de distinto ámbito».

${ }^{5}$ En palabras de García Roca: el carácter escueto y elástico de los preceptos constitucionales sobre la autonomía local ha constituido un pretexto para no extraerles toda su eficacia normativa.
} 
REALA. Nueva Época - N. ${ }^{\circ}$ 6, noviembre 2016 - ISSN: 1989-8975 - DOI: 10.24965/reala.v0i6.10390 - [Págs. 93-104]

La indeterminación competencial y la potestad sancionadora de los entes locales como presupuesto fallido para la sustitución de ...

Cristian Rodríguez Alonso

ción de los poderes en los que, territorialmente, se subsumen dichas entidades, bien sea el propio Estado o la Comunidad Autónoma en la que radica.

En este panorama, unido a la crisis económica actual, las corporaciones municipales han tratado, dentro del muy acotado e indefinido marco de sus competencias, realizar una labor innovadora y reinterpretativa posibilitando por medios de sus ordenanzas, con base en la potestad sancionadora de las Administraciones Públicas, sustituir (o suspender) las sanciones económicas impuestas a los ciudadanos como consecuencia de la infracción de dichas normas ${ }^{6}$ por la realización de trabajos en beneficio de la comunidad que, por consiguiente, extinguen la sanción económica.

Dicha práctica se ha extendido en los entes locales desde comienzos del siglo XXI como una forma de ofrecer alternativas al pago de la sanción pecuniaria al ciudadano, que, aunque a primera vista parezca una merma de ingresos en las arcas públicas, se compensa con la contraprestación recibida, es decir, la realización de los trabajos en beneficio de la comunidad en sustitución de la sanción económica supone la realización de tareas por el ciudadano, que dentro de las competencias del ente local, tendrán que ser desempeñadas de igual manera, o bien suponen una mejora o un rendimiento más óptimo del servicio o actividad a desempeñar.

Desde un punto de vista político-social, supone un gran beneficio para el ciudadano que puede, de manera voluntaria, evitar el pago de la sanción pecuniaria mediante la realización de dichas actividades. Pero, el principal problema radica en la imposibilidad, por parte de estos entes locales, de tipificar nuevas sanciones ya que esto supondría una vulneración flagrante del principio de legalidad debido a la inexistencia de poder legislativo en dichas entidades y por ende la imposibilidad de promulgar leyes que sustente dicha actuación.

Los municipios que se han aventurado a la regulación de dicha peculiaridad han sustentado sus decisiones en la aplicación analógica de una institución de Derecho Penal, como son los trabajos en beneficio de la comunidad, y en la interpretación que realiza el Tribunal Constitucional ${ }^{7}$ sobre los principios que inspiran el ordenamiento penal que pueden ser contemplados, con ciertas matizaciones, en el Derecho administrativo. Esta actuación, solo es posible cuando la normativa estatal o autonómica hayan previsto dicha posibilidad por medio de una Ley que habilite, a los entes locales encuadrados en su ámbito territorial, a efectuar la sustitución o suspensión de las sanciones económicas por ellos impuesta por trabajos en beneficios de la comunidad u otras medidas contempladas en dicha previsión legal; de lo contrario se vulneraría el principio de legalidad como se analizará a continuación.

\section{LA INDETERMINACIÓN LOCAL EN EL REPARTO DE COMPETENCIAS EN LA CONSTITUCIÓN DE 1978}

La Constitución Española, a diferencia de lo que sucede con los listados competenciales contenidos en los artículos 148 y 149 con relación a la distribución territorial del poder entre el Estado y las Comunidades Autónomas ${ }^{8}$, no contiene referencia explícita alguna a las competencias locales. De ahí que haya sido el Tri-

\footnotetext{
6 Basta citar como ejemplos de ordenanzas reguladoras de la sustitución de las sanciones administrativas por trabajos en beneficio de la comunidad, entre otras: Ordenanza Municipal sobre Ejecución Alternativa de Sanciones Económicas del Ayuntamiento de Conil de la Frontera (Cádiz), de 26 de marzo de 1999. Ordenanza municipal sobre la ejecución alternativa de sanciones económicas por medio de servicios en beneficio de la comunidad del Ayuntamiento de Algemesí (Valencia), de 28 de diciembre de 2009 . Ordenanza municipal reguladora de la conmutación de sanciones económicas por infracción de las ordenanzas municipales por trabajos en beneficio de la comunidad del Ayuntamiento de Granadilla de Abona (Santa Cruz de Tenerife), de 27 de Septiembre de 2013. Ordenanza municipal reguladora del procedimiento para el ejercicio de la potestad sancionadora del Ayuntamiento de Zaragoza (Zaragoza), de 31 de enero de 2014. Ordenanza Municipal reguladora de la Sustitución de Sanciones Económicas por la Realización de Trabajos en Beneficio de la Comunidad del Ayuntamiento de Noja (Cantabria), de 30 de abril de 2014.

7 Sentencia del Tribunal Constitucional 18/1981, de 8 de Junio de 1981, que dispone que «los principios inspiradores del orden penal son de aplicación, conciertos matices, al Derecho administrativo sancionador, dado que ambos son manifestaciones del ordenamiento punitivo del Estado, tal y como refleja la propia Constitución (artículo 25, principio de legalidad) y una muy reiterada jurisprudencia de nuestro Tribunal Supremo, hasta el punto de que un mismo bien jurídico puede ser protegido por técnicas administrativas y penales $(. .)$.$» .$

8 La Constitución española de 1978, ha optado por el sistema de enumeración de competencias para determinar las que puedan corresponder a las Comunidades Autónomas (artículo 148) y las que corresponden exclusivamente al Estado (artículo 149.1) con determinadas limitaciones que suponen una competencia compartida (artículo 149.2 y 149.3), sin embargo, ha omitido cualquier referencia al tema de las competencias municipales. FANLO LORAS, A (1990). Fundamentos constitucionales de la autonomía local. Centro de estudios constitucionales. Madrid.
} 
REALA. Nueva Época - N. ${ }^{\circ}$ 6, noviembre 2016 - ISSN: 1989-8975 - DOI: 10.24965/reala.v0i6.10390 - [Págs. 93-104]

La indeterminación competencial y la potestad sancionadora de los entes locales como presupuesto fallido para la sustitución de ...

Cristian Rodríguez Alonso

bunal Constitucional, el que ha determinado la relación entre los artículos 149.1.18. ${ }^{\mathrm{a}}$ y 137 de la Constitución española en orden a la atribución al Estado del título competencial para determinar el modelo competencial de los Municipios ${ }^{9}$.

Así, a diferencia de lo que sucede con el Estado y las Comunidades Autónomas, no existe en la Constitución un listado o una previsión competencial propia para la administración local, pero, en la medida que ésta constituye junto con aquellos un elemento más en la intrínseca configuración territorial del poder, es necesario considerar que también desde el nivel constitucional se deben extraer consecuencias en relación con las competencias locales. Así lo expresa Ortega Álvarez al determinar que, pese a que existe un reparto constitucional de competencias entre Estado y las Comunidades Autónomas, estos no pueden agotarlas totalmente entre sí ya que una parte del poder constitucional les es atribuido conceptualmente a los entes locales y este poder implica su intervención en todo lo que concierne a los asuntos de la comunidad local ${ }^{10}$.

Esta indeterminación de las competencias del Municipio, o al menos la referencia a ellas de modo genérico, es una cuestión que elude totalmente la Constitución aunque proclama y reitera el carácter autónomo de los Municipios dotándolos de personalidad jurídica plena ${ }^{11}$.

Los artículos 137 (apoyado por el 140 y el $141^{12}$ ) y el 149.1.18. ${ }^{a}$ de la Constitución española serán decisivos en la jurisprudencia constitucional para resolver esa indeterminación en la distribución de competencias y sobre todo la incidencia que el Estado y las Comunidades Autónomas abarcan en materia de régimen local.

El primero de ellos determina la organización territorial del estado en municipios, provincias y en las Comunidades Autónomas que se constituyan gozando todas estas entidades de autonomía ${ }^{13}$ para la gestión de sus respectivos intereses. El problema, como ya hemos apuntado, surge en la indeterminación de cuáles son esos respectivos intereses de las entidades locales que la Constitución deja sin resolver; al contrario de lo que sucede con las Comunidades Autónomas y el Estado.

Esta indeterminación no implica desvirtuar de contenido a las entidades garantizadas constitucionalmente sino que, al contrario, determina su existencia y garantiza que una parte de la cuota será indisponible por el legislador en tanto que la regulación que haga de estas entidades no pueden hacerlas irreconocibles como tales. Así fue manifestado por el Tribunal Constitucional al concluir que, en definitiva, la autonomía local consagrada en el artículos 137 CE (con el complemento de los artículos 140 y $141 \mathrm{CE}$ ) se traduce en una garantía institucional de los elementos esenciales o del núcleo primario del autogobierno de los entes locales territoriales, núcleo que debe necesariamente ser respetado por el legislador (estatal o autonómico, general o sectorial) para que dichas Administraciones sean reconocibles en tanto que entes dotados de autogobierno. En la medida en que el constituyente no predeterminó el contenido concreto de la autonomía local, el legislador constitucionalmente habilitado para regular materias de las que sea razonable afirmar que formen parte de ese núcleo indisponible podrá, ciertamente, ejercer en uno u otro sentido su libertad inicial de configuración, pero no podrá hacerlo de manera que establezca un contenido de la autonomía local incompatible con el marco general perfilado en los artículo 137, 140 y $141 \mathrm{CE}^{14}$.

Constatado que, a pesar de la indeterminación constitucional, el propio texto impide una regulación que desvirtúe el contenido de la institución local la garantía constitucional de la autonomía local y de las propias instituciones se establece en términos muy amplios e indeterminados. Como hemos podido observar, el principio de autonomía de las entidades locales no tiene un contenido constitucionalmente reglado y por ello es lícito y posible atribuir a aquéllas, unas u otras competencias en base a la expresión «gestión de sus respectivos intereses». A ello hay que añadir que la mayor parte de sectores o materias en las que las entidades locales tienen intereses directos son también materias en las que se atribuyen competencias legislativas 0 de ejecución a las Comunidades Autónomas en sus Estatutos.

\footnotetext{
9 Exposición de motivos de la Ley 27/2013, de 27 de diciembre, de racionalización y sostenibilidad de la Administración Local.

10 ORTEGA ÁLVAREZ, L (2011). Las competencias propias de las Corporaciones Locales, en Tratado de Derecho Municipal. Tomo I (dir. S. Muñoz Machado). lustel. Madrid.

11 SÁNCHEZ DÍAZ, J. L (1980): «Competencia y autonomía municipal», Anales de la Universidad de Murcia XXXIV: 421-436.

12 El artículo 137 establece que los Municipios «gozan de autonomía» y el artículo 140 garantiza su autonomía. El primero relaciona la autonomía con la gestión de intereses municipales y el segundo les atribuye como propias potestades de gobierno y administración. Sentencia del Tribunal Constitucional 32/1981, de 28 de julio.

${ }_{13}$ El Tribunal Constitucional ha considerado la autonomía local como el derecho de la comunidad local a participar a través de órganos propios en el gobierno y administración de cuantos asuntos le atañen constituyendo en todo caso un poder limitado que no puede oponerse al principio de unidad; Sentencia del Tribunal Constitucional 4/1981 de 2 de febrero.

14 Sentencia del Tribunal Constitucional 159/2001, de 5 de julio.
} 
REALA. Nueva Época - N. ${ }^{\circ}$ 6, noviembre 2016 - ISSN: 1989-8975 - DOI: 10.24965/reala.v0i6.10390 - [Págs. 93-104]

La indeterminación competencial y la potestad sancionadora de los entes locales como presupuesto fallido para la sustitución de ...

Cristian Rodríguez Alonso

Por todo esto, dado el carácter general y abstracto con que se reconoce constitucionalmente la garantía de la autonomía local, no parece suficiente, por sí misma, por lo que se requiere del legislador estatal para que lleve a cabo una definición más detallada de esa garantía con una finalidad protectora inclusive frente a los eventuales excesos centralizadores de la legislación autonómica ${ }^{15}$.

El fundamento que supone que sea el legislador estatal el encargado de disciplinar un contenido esencial, necesario y único para estas entidades se concreta en el artículo 149.1.18. ${ }^{a}$ de la Constitución en la expresión «bases del régimen jurídico de las Administraciones públicas», en virtud del cual el Tribunal Constitucional en su sentencia 32/1981, de 28 de julio, ha realizado la siguiente reflexión; «como titulares de un derecho a la autonomía constitucionalmente garantizada (artículos 137 y 140 de la Constitución), las comunidades locales no pueden ser dejadas en lo que toca a la definición de sus competencias y la configuración de sus órganos de gobierno a la interpretación que cada comunidad autónoma pueda hacer de ese derecho(...) La garantía constitucional es de carácter general y configuradora de un modelo de Estado, y ello conduce, como consecuencia obligada, a entender que corresponde al mismo la fijación de principios o criterios básicos en materia de organización y competencia de general aplicación en todo el Estado».

De acuerdo con esta doctrina, debe ser el legislador estatal, con carácter general y para todo tipo de materias, el que fije unos principios o bases relativas a las competencias locales, encontrando cobertura constitucional a esa encomienda estatal en el concepto mismo de bases del régimen jurídico de las Administraciones Públicas, por cuanto dicha expresión engloba a las Administraciones Locales ${ }^{16}$.

Por consiguiente al entroncar la expresión «régimen jurídico de las Administraciones Públicas» en lo que respecta a las Administraciones locales, el Tribunal Constitucional proclama la competencia del Estado para establecer las bases ${ }^{17}$ no solo en materias de organización, es decir, en los aspectos institucionales ${ }^{18}$ sino también en materia de competencia de los entes locales constitucionalmente necesarios.

De ahí, que sea el legislador estatal el que tenga que llevar a cabo su ordenación institucional, pero que, para preservar su individualidad, se recurriese a la técnica de la garantía institucional, que como expone Parejo Alfonso, «se trata de una técnica específica de protección frente al poder constituido y especialmente el legislador para impedir desde luego la suspensión de la institución pero también para evitar cualquier desvirtuación o lesión o incluso alteración ilegítimas de la misma» ${ }^{19}$.

Con esta técnica, de elaboración germánica, se pretende asegurar una imagen recognoscible desde el punto de vista sociológico e histórico de determinadas instituciones reconocidas constitucionalmente ya que las entidades locales se consideran elementos estructurales indispensables del orden constitucional que hay que preservar al menos en su núcleo esencial incluso frente al legislador ordinario sancionando con la nulidad por inconstitucional de aquellas normas que violenten ese núcleo indisponible.

Pero esta competencia estatal necesita de una serie de limitaciones que eviten que sea el propio estado quien, por medio de su regulación, vacíe de contenido a las entidades locales. Por ello, diversos autores como Velasco Caballero o Santamaría Pastor han determinado que existen límites intrínsecos y extrínsecos respecto a la competencia estatal. Respecto a los primeros, las bases se definen por su relación con las normas autonómicas de desarrollo, es decir la norma estatal sufre una autorrestricción debido a que ha de respetar que cada Comunidad Autónoma con competencia de «desarrollo legislativo» disponga de un ámbito para sus propias opciones políticas, de ahí el criterio jurisprudencial de que las bases estatales se han de expresar a través de normas principales ${ }^{20}$.

15 FUENTETAJA PASTOR, J. A (2013). Marco constitucional de la Administración local, en Manual de Derecho Local (dir. Carmen Fernández Rodríguez). lustel. Madrid.

${ }_{16}$ Sentencia del Tribunal Constitucional 25/1983, de 7 de abril; 76/1983, de 5 de agosto; 27/1987, de 27 de febrero; 99/1987, de 11 de junio y 214/1989, de 21 de diciembre.

17 Son los aspectos centrales o nucleares del régimen jurídico de una determinada materia o institución. Tienen un sentido positivo y otro negativo: el primero manifiesta los objetivos, fines y orientaciones generales en un sector del ordenamiento exigidos por la unidad del Estado y la igualdad de todos los ciudadanos; en un sentido negativo constituyen un límite al ejercicio de las competencias propias de las Comunidades Autónomas; Sentencia del Tribunal Constitucional 32/1981, de 28 de julio; 64/1982, de 4 de noviembre; 24/1985 de 12 de febrero, 143/2013, de 11 de julio entre otras.

18 Entendiendo tales aspectos como la estructura, organización y funcionamiento, potestades administrativas de los entes locales, régimen de actuación incluidas las relaciones administrativas y el sistema de controles. PAREJO ALFONSO, L (1981). Garantía institucional y autonomía locales. Instituto de Estudios de Administración Local. Madrid.

19 PAREJO ALFONSO, L (2011). La autonomía local en la Constitución, en Tratado de Derecho Municipal. Tomo I (dir. Santiago Muñoz Machado). lustel. Madrid.

20 VELASCO CABALLERO, F (2014). Títulos competenciales y garantía constitucional de autonomía local en la Ley de Racionalización y sostenibilidad de la Administración Local, en La Reforma de 2013 del régimen local español (coor. Juan Alfonso Santamaría Pastor). Madrid, Fundación Democracia y Gobierno Local. Madrid. 
Los límites extrínsecos vienen dados por la propia jurisprudencia constitucional al afirmar que la ley básica estatal (...) si excede de lo necesario para garantizar la institución de la autonomía local habrá invadido competencias comunitarias y será por ello inconstitucional ${ }^{21}$.

De acuerdo con lo expuesto, al legislador estatal no se le impone más límite que el del reducto indisponible o núcleo esencial de la institución que la Constitución garantiza entendiendo que, la garantía institucional no asegura un contenido concreto o un ámbito competencial determinado y fijado de una vez por todas, sino la preservación de una institución en términos recognoscibles para la imagen que de la misma tiene la conciencia social en cada tiempo y lugar.

En definitiva, los límites a la regulación del legislador estatal implican evitar una ruptura clara y contundente con la imagen comúnmente aceptada de la institución. Por lo tanto, desde el punto de vista competencial, la garantía de la autonomía local ex artículo 137 CE se proyecta en la exigencia de que el legislador ha de atenerse a un «mínimo competencial», que, como competencias propias, ha de reconocerse al ente local ${ }^{22}$.

Así, el legislador estatal será el encargado de establecer el régimen jurídico básico y necesario para las entidades locales tratando de aunar sus competencias en materia de legislación básica en dicha materia, la legislación de desarrollo de las Comunidades Autónomas en las materias en las que puedan concurrir con los intereses de las entidades locales y la potestad reglamentaria de éstas últimas. Dicho esto, será por medio de la Ley $7 / 1985$, de 2 de abril, Reguladora de las Bases del Régimen Local por la que el legislador estatal configure el contenido mínimo y esencial de las entidades locales configurándola el propio legislador en el preámbulo de la disposición como la norma institucional de los entes locales [...] que desarrolla la garantía constitucional de la autonomía local».

Por medio de esta regulación, se viene a concretar esa indeterminación constitucional respecto a las materias en los que los entes locales tienen poder de actuación al delimitar su ámbito competencial ${ }^{23}$ y lo que es más importante, se regula de manera específica el deber tanto del legislador autonómico como del estatal de asegurar a los entes locales el derecho a intervenir en aquellos asuntos que afecten directamente al círculo de sus intereses lo que conlleva un mayor halo de protección de su autonomía constitucionalmente garantizada.

\section{LA POTESTAD SANCIONADORA DE LOS ENTES LOCALES COMO INTENTO DE FUNDAMENTACIÓN DE LA SUSTITUCIÓN DE SANCIONES ADMINISTRATIVAS EN EL ÁMBITO DE SUS COMPETENCIAS POR TRABAJOS EN BENEFICIO DE LA COMUNIDAD}

Llegados a este punto hemos podido apreciar que, fruto de la indeterminación constitucional del ámbito competencial de los entes locales, ha surgido una importante problemática a la hora de concretar cuál es

21 Sentencia del Tribunal Constitucional 214/1989, de 21 de diciembre.

22 Sentencia del Tribunal Constitucional 109/1989, de 8 de junio.

23 El artículo 25 de la Ley 7/1985, de 2 de abril, Reguladora de las Bases del Régimen Local recoge las materias en las que los municipios ostentan competencia para la gestión de sus respectivos intereses.

a) Seguridad en lugares públicos.

b) Ordenación del tráfico de vehículos y personas en las vías urbanas.

c) Protección civil, prevención y extinción de incendios.

d) Ordenación, gestión, ejecución y disciplina urbanística; promoción y gestión de viviendas; parques y jardines, pavimentación de vías públicas urbanas y conservación de caminos y vías rurales.

e) Patrimonio histórico-artístico.

f) Protección del medio ambiente.

g) Abastos, mataderos, ferias, mercados y defensa de usuarios y consumidores.

h) Protección de la salubridad pública.

i) Participación en la gestión de la atención primaria de la salud.

j) Cementerios y servicios funerarios.

k) Prestación de los servicios sociales y de promoción y reinserción social.

l) Suministro de agua y alumbrado público; servicios de limpieza viaria, de recogida y tratamiento de residuos, alcantarillado y tratamiento de aguas residuales.

II) Transporte público de viajeros.

m) Actividades o instalaciones culturales y deportivas; ocupación del tiempo libre; turismo.

n) Participar en la programación de la enseñanza y cooperar con la Administración educativa en la creación, construcción y sostenimiento de los Centros Docentes públicos, intervenir en sus órganos de gestión y participar en la vigilancia del cumplimiento de la escolaridad obligatoria. 
REALA. Nueva Época - N. ${ }^{\circ}$ 6, noviembre 2016 - ISSN: 1989-8975 - DOI: 10.24965/reala.v0i6.10390 - [Págs. 93-104]

La indeterminación competencial y la potestad sancionadora de los entes locales como presupuesto fallido para la sustitución de ..

Cristian Rodríguez Alonso

el alcance de las potestades que ostentan los entes locales ${ }^{24} \mathrm{y}$, sobre todo, acerca de la flexibilización del artículo 25 de la Constitución que encierra la habilitación de la potestad sancionadora ${ }^{25}$ de los entes locales, lo que ha llevado a algunos municipios a desvirtuar el mandato constitucional hasta el punto de vaciarlo de contenido como ahora será expuesto.

Las entidades que integran la Administración local gozan de un ámbito de autonomía constitucionalmente consagrado y garantizado, enmarcado dentro de la esfera de sus intereses, denominado autonomía local como hemos venido apuntando. Pero resulta necesario que las mismas tengan la posibilidad de imponer consecuencias negativas a los autores de actos contrarios a las normas jurídicas aplicables dentro de sus límites territoriales, puesto que de modo contrario se vaciaría de contenido sus potestades ${ }^{26}$ y por ende la propia institución.

Como es sobradamente conocido, la Constitución española dispone en el citado artículo 25.1 que «nadie puede ser condenado o sancionado por acciones u omisiones que en el momento de producirse no constituyan delito, falta o infracción administrativa, según la legislación vigente en aquel momento».

El Tribunal Constitucional se apresuró a definir lo que habría de entenderse por «legislación vigente» para evitar, en primer lugar, que el ejercicio de la potestad sancionadora se llevase a cabo de una manera desmedida lo que provocase que se impusiesen sanciones sin respaldo legal alguno e incluso sin un procedimiento administrativo que garantizase los derechos del interesado.

$\mathrm{Y}$, en segundo lugar, para asentar el derecho fundamental a la legalidad sancionadora creando un blindaje de seguridad en los ámbitos limitativos de la libertad individual que obligatoriamente debía traducirse en la exigencia de predeterminación normativa de las conductas ilícitas y de las sanciones correspondientes.

El resultado de la labor del Tribunal Constitucional fue la construcción de una garantía material y formal según la cual las normas sancionadoras han de tener rango de ley y definir los supuestos de infracción y la imposición de sanciones. De esta manera el derecho reconocido en el artículo 25.1 aplicable al ordenamiento administrativo sancionador ha incorporado una doble garantía para los ciudadanos; la primera, de orden material, relativa a la exigencia de una predeterminación normativa de las conductas que se consideren ilícitas y de sus sanciones correspondientes: y la segunda de carácter formal, la necesidad de reserva de Ley para regular los tipos de infracción administrativa.

Esta exigencia que establece el ordenamiento jurídico, en el sentido de imponer la necesaria habilitación legal para poder ejercer la potestad sancionadora cobra una mayor importancia en el ámbito municipal, debido, principalmente, a la falta de potestad legislativa de las entidades locales puesto que, si bien estas administraciones públicas disponen de autonomía para la gestión de sus respectivos intereses, no disponen de competencia para elaborar normas con rango de ley.

Este principio de reserva de Ley o principio de legalidad tiene diferente alcance según se trata de Derecho Penal o de Derecho Administrativo sancionador. Así, el Tribunal Constitucional ha estimado que en el caso del derecho penal se trata de una reserva absoluta de Ley como se recoge en la Sentencia de 30 de marzo de 1981 que señala que «se infiere de tal precepto (artículo 25 de la Constitución) que la acción u omisión ha de estar tipificada como delito o falta en la legislación penal (principio de tipicidad) y asimismo que la Ley penal que contenga la tipificación del delito o falta y su correspondiente pena ha de estar siempre vigente en el momento de producirse la acción u omisión».

En el caso del derecho administrativo, el Tribunal Constitucional estimó que la reserva de ley no puede ser tan estricta en relación con la regulación de las sanciones e infracciones administrativas como por referencia a los tipos y sanciones penales en sentido estricto ${ }^{27}$. Por ello, autores como Parada estiman que en el caso del Derecho Penal se trata de una reserva absoluta de ley mientras que en el derecho administrativo hablamos de cobertura legal teniendo en cuenta que en el primer caso la ley ha de cubrir por entero tanto la

24 Artículo 4.1 de la Ley 7/1985, de 2 de abril, reguladora de las Bases del Régimen Local: En su calidad de Administraciones públicas de carácter territorial, y dentro de la esfera de sus competencias, corresponden en todo caso a los Municipios (...)f) Las potestades (...) sancionadora.

25 La potestad sancionadora es la facultad que tienen las Administraciones Públicas de corregir los incumplimientos del ordenamiento jurídico mediante la imposición de un mal. MUÑOZ MACHADO, S (2011). Tratado de Derecho Municipal. Tomo 1. Iustel. Madrid.

${ }_{26}$ Las potestades no son sino parcelas en las que se distribuye la autonomía que corresponde a las administraciones públicas territoriales (Estado, comunidades autónomas y entidades locales), entendiendo por «autonomía» como un poder público limitado de organización y de ordenación, expresado en un determinado ámbito de intereses colectivos. FERNÁNDEZ MONTALVO, R (2007): «EI principio de reserva de ley en materia de competencia local: en especial el ejercicio de la potestad sancionadora», Manuales de formación continuada, XLIV: 485-660.

27 Sentencia del Tribunal Constitucional 42/1987, de 7 de abril. 
REALA. Nueva Época - N. ${ }^{\circ}$ 6, noviembre 2016 - ISSN: 1989-8975 - DOI: 10.24965/reala.v0i6.10390 - [Págs. 93-104]

La indeterminación competencial y la potestad sancionadora de los entes locales como presupuesto fallido para la sustitución de ..

Cristian Rodríguez Alonso

previsión de la penalidad como la descripción de la conducta ilícita, mientras que, en el principio de cobertura legal ${ }^{28}$ de las sanciones administrativas, solo se exige cubrir con Ley formal una descripción genérica de las conductas sancionables y de las clases y cuantía de las sanciones pero, con posibilidad de remitir a la potestad reglamentaria la descripción pormenorizada ${ }^{29}$.

La exigencia constitucionalmente establecida de la necesaria cobertura legal para que los entes locales, en el caso que nos ocupa, puedan ejercer la potestad sancionadora no solo implica el respeto al principio de legalidad si no también, necesariamente, el respeto al principio de tipicidad. Estas exigencias fueron plasmadas en dos textos básicos e inspiradores de toda actuación de la administración; en primer lugar, con carácter general para las Administraciones Públicas, la Ley 40/2015, de 1 de octubre, de Régimen Jurídico del Sector Público en cuyo artículo 27.1 establece el principio de legalidad (solo constituyen infracciones administrativas las vulneraciones del ordenamiento jurídico previstas como tales por Ley) y el principio de tipicidad recogido en el 27.2 (únicamente por la comisión de infracciones administrativas podrán imponerse sanciones que, en todo caso, estarán delimitadas por Ley).

En segundo lugar, la Ley 7/1985 de 2 de abril, reguladora de las Bases del Régimen Local, también recoge estas exigencias de los principios de legalidad y tipicidad en sendos artículos 139-14130. Así, éste primer artículo establece que "para la adecuada ordenación de la convivencia de interés local y del uso de sus servicios, equipamientos, infraestructuras, instalaciones y espacios públicos, los entes locales podrán, en defecto de normativa sectorial específica, establecer los tipos de las infracciones e imponer sanciones por el incumplimiento de deberes, prohibiciones o limitaciones contenidos en las correspondientes ordenanzas, de acuerdo con los criterios establecidos en los artículos siguientes». Finalmente, después de proceder a clasificar las infracciones en muy graves, graves y leves (artículo 140) establece el artículo 141 como único tipo de sanción la multa (salvo que exista previsión legal distinta).

Con ello, unido a la interpretación y regulación constitucional del principio de legalidad y de tipicidad de las infracciones administrativas no cabría la imposición de cualquier otro tipo de sanción que no estuviese prevista en una norma con rango legal, puesto que lo contrario supondría la vulneración del principio de legalidad y con ello la nulidad de la disposición.

Como hemos visto, este principio de legalidad y tipicidad consagrado en el artículo 25 de la Constitución se erige a la categoría de derecho fundamental (al estar ubicado en la sección $1 .^{\text {a }}$ del capítulo II del título I de la CE) supone una consecuencia correlativa del genérico previsto en el artículo 9.3, así como resulta coherente con los postulados constitucionales de la Administración pública previstos en el artículo $103 \mathrm{CE}$, fundamentalmente de su «vinculación a la Ley y al Derecho».

Por lo que hemos plasmado hasta ahora, partiendo de la regulación constitucional y siguiendo los postulados legales de nuestro ordenamiento, los entes locales a la hora de proceder al ejercicio de la potestad sancionadora deben sustentar su actuación en una norma de rango legal que habilite su actuación. Este principio ha sido matizado por el Tribunal Constitucional al exponer que «la exigencia de ley para la tipificación de infracciones y sanciones ha de ser flexible en materias donde, por estar presente el interés local, existe un amplio campo para la regulación municipal y siempre que la regulación local la apruebe el Pleno del Ayuntamiento».

Esta flexibilidad no sirve, con todo, para excluir de forma tajante la exigencia de ley. Y ello porque la mera atribución por ley de competencias a los Municipios -conforme a la exigencia del artículo 25.2 de la Ley 7/1985, de 2 de abril, reguladora de las bases del Régimen Local- no contiene en sí la autorización para que cada Municipio tipifique por completo y según su propio criterio las infracciones y sanciones administrativas en aquellas materias atribuidas a su competencia (...) La flexibilidad alcanza al punto de no ser exigible una definición de cada tipo de ilícito y sanción en la ley, pero no permite la inhibición del legislador ${ }^{31}$.

Del artículo 25.1 CE derivan dos exigencias mínimas, que se exponen a continuación. En primer término, y por lo que se refiere a la tipificación de infracciones, corresponde a la ley la fijación de los criterios mínimos de antijuridicidad conforme a los cuales cada Ayuntamiento puede establecer tipos de infracciones;

\footnotetext{
${ }^{28}$ La cobertura legal supone una regulación mínima en la Ley de los tipos y sanciones y en concreto de los límites de éstas. Sentencia del Tribunal Constitucional 42/1987, de 7 de abril.

29 PARADA VÁZQUEZ, R (2013). Derecho Administrativo II. Régimen jurídico de la actividad administrativa. Open. Madrid.

30 Se encuadra dentro del nuevo Título XI de la Ley $7 / 1985$, de 2 de abril, reguladora de las Bases del Régimen Local (relativo a la tipificación de infracciones y sanciones por las entidades locales en determinadas materias) introducido por la Ley 57/2003, de 16 de diciembre.

${ }^{31}$ Sentencia del Tribunal Constitucional 132/2001, de 8 de junio.
} 
REALA. Nueva Época - N. ${ }^{\circ}$ 6, noviembre 2016 - ISSN: 1989-8975 - DOI: 10.24965/reala.v0i6.10390 - [Págs. 93-104]

La indeterminación competencial y la potestad sancionadora de los entes locales como presupuesto fallido para la sustitución de ..

Cristian Rodríguez Alonso

no se trata de la definición de tipos -ni siquiera de la fijación de tipos genéricos de infracciones luego completables por medio de Ordenanza Municipal- sino de criterios que orienten y condicionen la valoración de cada Municipio a la hora de establecer los tipos de infracción.

En segundo lugar, y por lo que se refiere a las sanciones, del artículo $25.1 \mathrm{CE}$ deriva la exigencia, al menos, de que la ley reguladora de cada materia establezca las clases de sanciones que pueden establecer las ordenanzas municipales; tampoco se exige aquí que la ley establezca una clase específica de sanción para cada grupo de ilícitos, sino una relación de las posibles sanciones que cada Ordenanza Municipal puede predeterminar en función de la gravedad de los ilícitos administrativos que ella misma tipifica ${ }^{32}$.

Por todo lo expuesto, no cabe si no concluir que el artículo 25 de la Constitución (en relación con el 9.3 y el 103) cuando consagra los principios de legalidad y tipicidad de las infracciones administrativas lo hace con carácter concreto y a pesar de la interpretación flexible que ha realizado el Tribunal Constitucional no puede llegar al punto de que los Ayuntamientos por medio de sus ordenanzas desvirtúen dicha previsión constitucional y lleguen a la ruptura y el fraude de la Constitución a pesar de que las decisiones de tipificar como una nueva sanción los trabajos en beneficio de la comunidad pueda, desde un punto de vista políticosocial, favorecer al ciudadano ${ }^{33}$.

Dicho esto, supone la nulidad por inconstitucional de aquellas ordenanzas en virtud de las cuales se haya procedido a sustituir o suspender la sanción administrativa por trabajos en beneficio de la comunidad en ausencia de previsión legal; un ejemplo de ello sería la Ordenanza municipal reguladora de la conmutación de sanciones económicas por infracción de las ordenanzas municipales por trabajos en beneficio de la comunidad del Ayuntamiento de Granadilla de Abona (Santa Cruz de Tenerife), de 27 de Septiembre de 2013 ya que con ella, sin previsión legal alguna, se crea ex novo una sanción administrativa.

Con todo lo expuesto, llegamos a la conclusión que estaríamos ante una vulneración del principio de legalidad y de tipicidad de las sanciones administrativas (artículos 25 de la Constitución, 139-141 de la Ley $7 / 1985$, de 2 de abril, reguladora de las bases del Régimen Local), lo que supondría la nulidad de la disposición normativa, en los supuestos en que por medio de ordenanzas locales los Ayuntamientos proceden, sin previa cobertura legal, a tipificar por medio de la sustitución de la sanción pecuniaria, a los trabajos en beneficio de la comunidad.

Si bien es cierto que algunos sectores doctrinales ha querido ver en el artículo 55 del Real Decreto Legislativo 781/1986, de 18 de abril, por el que se aprueba el Texto Refundido de las disposiciones legales vigentes en materia de Régimen Local (en la esfera de su competencia, las Entidades locales podrán aprobar Ordenanzas y Reglamento [...] En ningún caso contendrán preceptos opuestos a las leyes) una vinculación negativa del principio de legalidad, en virtud del cual aquellas ordenanzas cuyas previsiones no se opusiesen a las Leyes permitirían la tipificación como sanción de los trabajos en beneficio de la comunidad. Esta tesis ha sido seguida por autores como Nieto al señalar que los resultados de esta interpretación tan superficial [la que niega a las ordenanzas la posibilidad de tipificar infracciones praeter legem] pueden ser catastróficos en la práctica administrativa local, dado que se arrebata a las entidades locales la posibilidad de acompañar sus mandatos y prohibiciones con una conminación para los supuestos de incumplimiento ${ }^{34}$.

Por su parte, Parejo Alfonso estima que las ordenanzas locales cumplen el requisito de la reserva de ley desde una perspectiva institucional y democrática [...] la ley exigida puede ser sustituida por cualquier otra norma democráticamente producida en aquellas organizaciones que carecen de una Asamblea con potestades legislativas como es el caso de las entidades locales ${ }^{35}$.

Incluso se ha producido algún pronunciamiento de la jurisprudencia ${ }^{36}$ donde se desvirtúa el principio de legalidad y tipicidad manifestando que «la tipificación de la que se habla no podrá hacerse por ordenanza más que en el supuesto de que se trate de la ordenación del uso de bienes o la organización de servicios que supongan potestades implícitas y siempre que no se haya efectuado anteriormente tal tipificación por ley estatal o autonómica».

32 ORDUÑA PRADA, E (2001): «Ordenanza municipal y potestad sancionadora: la sorprendente concisión de la STC 132/2001, de 8 de junio», Revista de Estudios de la Administración Local y Autonómica, CCLXXXVI: 363-373.

${ }_{33}$ Sentencia de Tribunal Constitucional 305/1993, de 25 de octubre; el artículo 25.1 CE obliga al legislador a regular por sí mismo los tipos de infracciones administrativas y las sanciones que le sean de aplicación, sin que sea posible que, a partir de la Constitución, se puedan tipificar nuevas infracciones ni introducir nuevas sanciones o alterar el cuadro de las existentes por una norma reglamentaria cuyo contenido no esté suficientemente predeterminado o delimitado por otra con rango de Ley.

34 NIETO GARCÍA, A (2002). Derecho administrativo sancionador. Tecnos. Madrid.

35 PAREJO ALFONSO, L (1998). La potestad normativa local. Marcial Pons. Madrid.

36 Sentencia del Tribunal Supremo de 29 de septiembre de 2003. 
REALA. Nueva Época - N. ${ }^{\circ}$ 6, noviembre 2016 - ISSN: 1989-8975 - DOI: 10.24965/reala.v0i6.10390 - [Págs. 93-104]

La indeterminación competencial y la potestad sancionadora de los entes locales como presupuesto fallido para la sustitución de ..

Cristian Rodríguez Alonso

La doctrina de la vinculación negativa del principio de legalidad sostiene que la Administración está vinculada negativamente a la ley, es decir, puede libre y válidamente realizar cualquier actuación, sin necesidad, por tanto, de contar con una previa habilitación legal, con la única condición de no contradecir las leyes existentes ${ }^{37}$

Muy distinta es la posición de la Administración Pública a ese respecto. Ésta no es libre de hacer todo lo que quiera salvo que la Ley se lo prohíba, que es el principio que inspira la sujeción a Derecho de los ciudadanos, sino que, por el contrario, la Administración sólo puede hacer lo que la Ley y el Derecho le permitan (artículos 9.1, 9.3y 103.1 de la Constitución): la forma en que queda la Administración sujeta a Derecho responde a la máxima "está prohibido lo que no está permitido» ("quae non sunt permissae prohibita intelliguntur»).

La actuación de la Administración está orientada por el principio de legalidad en su vertiente positiva, es decir, solamente puede hacer aquello que la ley le autorice; esto es, la ley opera como fundamento previo y necesario de la actuación de la administración. En palabras de García de Enterría ${ }^{38}$, la Administración pública requiere para su actuación una habilitación legal previa.

La razón de esta distinta posición es explicable a partir de la existencia de la separación de poderes que coloca al Parlamento y a la Ley, que es su producto, en directa relación con el titular de la soberanía y, en consecuencia, somete la Administración al imperio de la Ley. La Administración existe en virtud de la Constitución y en su actuación está sometida al imperio de la Ley y no al margen de la Ley. Es decir que sólo puede hacer lo que la Constitución y la Ley le permitan.

Esta diferenciación entre la actitud del ciudadano y de la Administración ante la Ley es recogida en la Sentencia del Tribunal Constitucional 83/1984, de 24 de julio, la cual declara con carácter general que el principio general de libertad que la Constitución (artículo 1.1) consagra autoriza a los ciudadanos a llevar a cabo todas aquellas actividades que la Ley no prohíba, o cuyo ejercicio no subordine a requisitos o condiciones determinadas y el principio de legalidad (artículo 9.3 y 103.1) impide que la Administración dicte normas sin la suficiente habilitación legal. Continúa diciendo el alto tribunal que si bien la reserva de ley no excluye la posibilidad de que las leyes contengan remisiones a normas reglamentarias, sí que impide que esas remisiones hagan posible una regulación independiente y no claramente subordinada a la ley, lo que supondría una degradación de la reserva formulada por la Constitución al legislador.

Asimismo, el Tribunal Constitucional expone el ordenamiento administrativo sancionador, incorpora una doble garantía: la primera, de orden material y de alcance absoluto, refleja la especial trascendencia del principio de seguridad en dichos ámbitos limitativos de la libertad individual y se traduce en la imperiosa exigencia de predeterminación normativa de las conductas ilícitas y de las sanciones correspondientes. La segunda, de carácter formal, se refiere al rango necesario de las normas tipificadoras de aquellas conductas reguladoras de estas sanciones, que aunque no excluye la cooperación entre Ley y Reglamento en este ámbito, impone inexcusablemente que exista una necesaria cobertura de la potestad sancionadora de la Administración en una norma legal habida cuenta del carácter excepcional que los poderes sancionatorios en manos de la Administración presentan ${ }^{39}$.

Por otro lado, considerar la equiparación de una ordenanza, fruto de la potestad reglamentaria local, a una ley formal supondría una quiebra del principio de legalidad y de los principios constitucionales al igual que supondría elevar al reglamento a la condición de Ley pero sin todas las garantías que esto entraña, así, como considerar que el ente local ostenta (al igual que el Estado y las Comunidades Autónomas) un poder legislativo propio, lo cual generaría una situación de mutación constitucional en detrimento de la misma.

Respecto al pronunciamiento jurisprudencial, permitir la tipificación de nuevos tipos de sanciones, en defecto de normativa estatal o autonómica, supondría deslegalizar las previsiones de los artículos 139-141 de la Ley $7 / 1985$, de 2 de abril, reguladora de las Bases del Régimen Local, en virtud de los cuales solo permite en defecto de normativa sectorial un tipo de sanción que es la multa económica.

37 GALÁN GALÁN, A (2001). La potestad normativa autónoma local. Atelier. Barcelona.

Esta tesis sigue la máxima "está permitido todo lo que no está prohibido» ("permissum videtur in omne, quod non prohibitum»), pero estaríamos hablando, en palabras de Tomás de la Quadra-Salcedo Fernández del Castillo, de la posición del ciudadano ante el ordenamiento jurídico, dado que subraya la idea inicial y general de libertad - «está permitido todo»- y el carácter de excepción o de previsión expresa - «salvo lo que está prohibido»-que se exige para limitar ese espacio inicial de libertad.

${ }^{38}$ GARCÍA DE ENTERRÍA, E (1994). La lengua de los Derechos. La formación del Derecho Público europeo tras la Revolución Francesa. Alianza Universidad. Madrid.

39 Sentencia del Tribunal Constitucional 75/2002, de 8 abril. 
REALA. Nueva Época - N. ${ }^{\circ}$ 6, noviembre 2016 - ISSN: 1989-8975 - DOI: 10.24965/reala.v0i6.10390 - [Págs. 93-104]

La indeterminación competencial y la potestad sancionadora de los entes locales como presupuesto fallido para la sustitución de ...

Cristian Rodríguez Alonso

En definitiva, la regulación constitucional de los principios de legalidad y tipicidad de las infracciones administrativas, unido a su desarrollo legal impide que por medio de las ordenanzas locales se tipifique como sanción a los trabajos en beneficio de la comunidad salvo que ya exista tal tipificación en una norma sectorial o bien que exista una regulación estatal o autonómica que permita que los entes locales se acojan a dicho régimen al subsumirse dentro de ámbito territorial y competencial. Cabe citar como ejemplos de normas autonómicas que en el marco de su regulación posibilitan la sustitución de las sanciones administrativas por trabajos en beneficio de la comunidad a la Ley $2 / 2003$, de 13 de marzo, de convivencia y ocio de Extremadura ${ }^{40}$, la Ley $7 / 2006$, de 24 de octubre, de potestades administrativas en materia de determinadas actividades de ocio en los espacios abiertos de los municipios de Andalucía ${ }^{41}$, la Ley 22/2006, de 4 de julio, de Capitalidad y de Régimen Especial de Madrid ${ }^{42}$ o la Ley 22/1998, de 30 de diciembre, de la Carta Municipal de Barcelona.

Especial consideración tiene esta última disposición normativa ya que fue objeto de recurso de casación ante el Tribunal Supremo. El artículo 29.3 de la citada ley catalana expone que «el incumplimiento de las prescripciones contenidas en las ordenanzas y disposiciones generales municipales y órdenes individuales es sancionable con una multa municipal. Cuando la ordenanza municipal lo establezca, de acuerdo con la Ley o, en su defecto, previo consentimiento de la persona afectada, puede sustituirse la multa pecuniaria por trabajos para la comunidad»; el problema radica en que el Ayuntamiento de Barcelona en una de sus ordenanzas además de la posibilidad de la sustitución de las sanciones administrativas por trabajos en beneficio de la comunidad incluyó otras medidas (no contempladas en la Ley 22/1998, de 30 de diciembre, de la Carta Municipal de Barcelona) tales como sesiones formativas y participación en actividades cívicas. Ante esto, el Tribunal Supremo expuso que el precepto (donde se contemplan los supuestos de sustitución de la sanción administrativa por estas otras medidas) debe ser anulado, excepción hecha de la previsión referida a trabajos para la comunidad ${ }^{43}$.

Con estas reflexiones apreciamos la importancia de la previa regulación legal de esas distintas medidas sustitutivas de la sanción administrativa para posibilitar que las ordenanzas pueda abarcar la sustitución de la sanción económica por trabajos en beneficio de la comunidad (u otras medidas); pero todo ello teniendo siempre presente que sin la regulación por medio de una Ley que lo habilite la actuación del ente local estaría viciada de nulidad al vulnerar el principio de legalidad.

La necesariedad de una ley para la introducción de nuevos tipos de infracción no es solo una característica propia de nuestro ordenamiento ya que estados que forman parte de nuestro entorno europeo han seguido los mismos postulados. Así, por ejemplo, en el caso de Alemania, el Gesetz über Ordnungswidrigkeiten, de 19 de febrero de 1987, contempla la posibilidad de acordar la sustitución de la multa administrativa impuesta a un menor por otras prestaciones entre las que se encuentra la realización de prestaciones en beneficio de la comunidad.

Finalmente, otro de los elementos empleados por las ordenanzas locales como medio para «posibilitar» la inclusión de los trabajos en beneficio de la comunidad como medida sustitutiva de la sanción económica es equiparar el ordenamiento sancionador administrativo con el ordenamiento penal. Para ello hacen eco de un pronunciamiento del Tribunal Constitucional ${ }^{44}$ que dispone que «los principios inspiradores del orden penal son de aplicación, conciertos matices, al Derecho administrativo sancionador, dado que ambos son manifestaciones del ordenamiento punitivo del Estado, tal y como refleja la propia Constitución (artículo 25, principio de legalidad) y una muy reiterada jurisprudencia de nuestro Tribunal Supremo, hasta el punto de que un mismo bien jurídico puede ser protegido por técnicas administrativas y penales (...)».

Pero al utilizar dicho pronunciamiento se "olvidan» de sintetizar a que principios y matizaciones se refiere dicho tribunal. Esto es realizado por el Tribunal Supremo en diversas sentencias donde recoge que

40 La Ley extremeña dispone que la realización de trabajos en beneficio de la comunidad se aplique a menores de 18 años y mayores de 16 años por la comisión de infracciones tipificadas en esa Ley (artículos 21 y siguientes de la Ley extremeña).

41 En el caso de la Ley andaluza, si la infracción se cometiese por personas menores de edad, mayores de 16años, la multa impuesta podrá ser sustituida, con su consentimiento expreso, por la realización de prestaciones no retribuidas de interés social a favor del municipio (artículo 9.3 de la Ley andaluza).

42 En la imposición de sanciones por el incumplimiento de deberes, prohibiciones o limitaciones contenidos en las ordenanzas por resolución motivada del órgano que resuelva el expediente sancionador, se podrá sustituir la sanción económica por trabajos en beneficios de la comunidad, la asistencia obligatoria a cursos de formación, a sesiones individualizadas o cualquier otra medida alternativa que tenga la finalidad de sensibilizar al infractor sobre cuáles son las normas de conducta en el espacio urbano o reparar el daño moral de las víctimas (artículo 52.3 de la Ley madrileña).

43 Sentencia del Tribunal Supremo de 18 de octubre de 2011.

4444 Sentencia del Tribunal Constitucional 18/1981, de 8 de Junio. 
REALA. Nueva Época - N. ${ }^{\circ}$ 6, noviembre 2016 - ISSN: 1989-8975 - DOI: 10.24965/reala.v0i6.10390 - [Págs. 93-104]

La indeterminación competencial y la potestad sancionadora de los entes locales como presupuesto fallido para la sustitución de ...

Cristian Rodríguez Alonso

los principios aplicables son el de legalidad, el de tipicidad de las infracciones y el de un procedimiento con todas las garantías. Así, Sentencias de la Sala Cuarta del Tribunal Supremo de 29 de Septiembre y de 10 de noviembre de 1980. La jurisprudencia se ha encargado de matizar ciertas diferencias entre el orden punitivo ordinario y el administrativo, aludiendo a una atenuación del rigor del primero en el segundo y a una mayor flexibilidad de éste siempre que se respeten los fundamentales principios de la tipicidad de la infracción y la legalidad de la pena, lo que veda a la Administración el ejercicio en esta materia de toda facultad creadora, estando imposibilitada de sancionar un supuesto diferente del previsto en la norma, o con pena diferente a la establecida en la misma.

Los principios esenciales reflejados en el artículo 24 de la Constitución en materia de procedimiento han de ser aplicables a la actividad sancionadora de la Administración, en la medida necesaria para preservar los valores esenciales que se encuentran en la base del precepto, y la seguridad jurídica que garantiza el artículo 9 de la Constitución [...] debemos afirmar ahora que tales valores no quedarían salvaguardados si se admitiera que la Administración, por razones de orden público, puede incidir en la esfera jurídica de los ciudadanos imponiéndoles una sanción sin observar procedimiento alguno, y, por tanto, sin posibilidad de defensa previa a la toma de la decisión, con la consiguiente carga de recurrir para evitar que tal acto se consolide y haga firme. Por el contrario, la garantía del orden constitucional exige que el acuerdo se adopte a través de un procedimiento en el que el presunto inculpado tenga oportunidad de aportar y proponer las pruebas que estime pertinentes y alegar lo que a su derecho convenga.

Con esta última reflexión se cercan todas las posibilidades para que por medio de una ordenanza se tipifiquen sanciones e infracciones diferentes a las contempladas en una norma con rango legal así como la posibilidad de proceder a la sustitución de dicha sanción pecuniaria por trabajos en beneficio de la comunidad.

\section{CONCLUSIÓN}

La autonomía local, constitucionalmente entendida, es fruto de una continua reinterpretación e intento de delimitación debido a la indeterminación competencial de ésta en el texto constitucional. Todo ello ha llevado a los intentos por parte de los entes locales de tratar de equiparar su actuación al resto de poderes territoriales del estado vaciando de contenido los mandatos constitucionales de respeto al principio de legalidad y tipicidad a la hora de tipificar nuevas sanciones, o más bien, tratando de flexibilizar tanto dichos principios que se acaban quebrando.

La potestad sancionadora de los entes locales se encuentra, como hemos expuesto, limitada y subordinada a la promulgación de una Ley habilitante que, hasta que no se produzca una modificación normativa, se limitará a la imposición de sanciones económica a excepción de aquellas situaciones donde una ley estatal o autonómica, sectorial o no, establezcan tipos infractores diferentes a la multa ya que, hasta ese momento, la actuación de los entes locales seguirá supeditada al único tipo de sanción tipificada; la multa.

Desde otro punto de vista, debe destacarse que las recientes ordenanzas resultan innovadoras en la búsqueda de respuestas a las infracciones a través de fórmulas distintas a la mera aplicación de una multa, incorporando opciones novedosas al respecto como los trabajos en beneficio de la comunidad y las medidas socioeducativas como medidas sustitutivas de la multa ${ }^{45}$.

A pesar de ello, la política municipal no puede superar aquello para lo que ha nacido, el respeto del ordenamiento jurídico y el cumplimiento de la legalidad si no que debe actuar dentro del marco y los límites que el entramado legal supone. Es cierto, que desde el punto de vista político-social, la posibilidad de evitar al ciudadano un gravamen como es la sanción pecuniaria goza de gran atractivo pero permitir dicha vulneración, no solo del texto constitucional si no también de las normas básicas de las entidades locales, supondría atentar contra los principios de la propia organización social del respeto a la soberanía.

Quizás la solución solo pase por un pequeño cambio en la normativa (un pequeño apéndice que establezca la posibilidad de tipificar nuevas infracciones a las entidades locales, por ejemplo, por medio de la modificación del artículo 141 de la Ley 7/1985, de 2 de abril, reguladora de las Bases del Régimen Local) o simplemente por medio de, en palabras de Entrena Cuesta, la expansión a través de la cooperación de las actividades y la coordinación de las potestades de los Municipios entre sí y con los restantes entes públicos que permita bien un cambio legislativo estatal que habilite a todos las entidades locales a introducir nuevas

45 PEMÁN GAVÍN, I (2003). El sistema sancionador español. Hacia una teoría general de las infracciones y sanciones administrativas. CEDECS. Barcelona. 
REALA. Nueva Época - N. ${ }^{\circ}$ 6, noviembre 2016 - ISSN: 1989-8975 - DOI: 10.24965/reala.v0i6.10390 - [Págs. 93-104]

La indeterminación competencial y la potestad sancionadora de los entes locales como presupuesto fallido para la sustitución de ...

Cristian Rodríguez Alonso

sanciones administrativas o bien fruto de la colaboración y aplomo con las Comunidades Autónomas para tratar de garantizar la igualdad de los ciudadanos en cada término autonómico.

En definitiva, aunque pueda parecer, a simple vista, que se trata de una medida de las entidades locales que busca la garantía y la facilidad de oportunidades en los ciudadanos, no podemos dejar atrás el razonamiento defendido y la vulneración de principios básicos y estructurales de nuestro ordenamiento como es el principio de legalidad, base de nuestro constitucionalismo; ya que obviar dicha vulneración supondría dotar a la autonomía local de un poder ilimitado y exorbitante capaz de dejar sin efecto aspectos, de tal calado, como la consagración constitucional de la tipicidad y legalidad de las sanciones aniquilando uno de los preceptos que gozan de la mayor protección en nuestra Constitución (artículo 25).

\section{BIBLIOGRAFÍA}

AJA FERNÁNDEZ, E (1999). El Estado Autonómico. Federalismo y hechos diferenciales. Alianza. Madrid.

DOMINGO ZABALLOS, M. J (2013). Comentarios a la Ley Básica de Régimen Local. Tomo Il. Aranzadi. Navarra.

FANLO LORAS, A (1990). Fundamentos constitucionales de la autonomía local. Centro de estudios constitucionales. Madrid.

FERNÁNDEZ MONTALVO, R (2007): «El principio de reserva de ley en materia de competencia local: en especial el ejercicio de la potestad sancionadora», Manuales de formación continuada, XLIV: 485-660.

FUENTETAJA PASTOR, J. A (2013). Marco constitucional de la Administración local, en Manual de Derecho Local (dir. Carmen Fernández Rodríguez). lustel. Madrid.

GALÁN GALÁN, A (2001). La potestad normativa autónoma local. Atelier. Barcelona.

GARCÍA DE ENTERRÍA, E (1994). La lengua de los Derechos. La formación del Derecho Público europeo tras la Revolución Francesa. Alianza Universidad. Madrid.

LLISET BORREL, F (2001). Manual de Derecho Local. El consultor de los Ayuntamientos y de los Juzgados. Madrid.

MUÑOZ MACHADO, S (2011). Tratado de Derecho Municipal. Tomo 1. Iustel. Madrid.

NIETO GARCÍA, A (2002). Derecho administrativo sancionador. Tecnos. Madrid.

ORDUÑA PRADA, E (2001): «Ordenanza municipal y potestad sancionadora: la sorprendente concisión de la STC 132/2001, de 8 de junio», Revista de Estudios de la Administración Local y Autonómica, CCLXXXVI: 363-373.

ORTEGA ÁLVAREZ, L (2011). Las competencias propias de las Corporaciones Locales, en Tratado de Derecho Municipal. Tomo I (dir. S. Muñoz Machado). lustel. Madrid.

PARADA VÁZQUEZ, J. R (2013). Derecho Administrativo II. Régimen Jurídico de la actividad administrativa. Open. Madrid.

PAREJO ALFONSO, L (1981). Garantía institucional y autonomía locales. Instituto de Estudios de Administración Local. Madrid.

- (1998). La potestad normativa local. Marcial Pons. Madrid.

- (2011). La autonomía local en la Constitución, en Tratado de Derecho Municipal. Tomo I (dir. Santiago Muñoz Machado). lustel. Madrid.

PEMÁN GAVÍN, I (2003). El sistema sancionador español. Hacia una teoría general de las infracciones y sanciones administrativas. CEDECS. Barcelona.

REQUEJO RODRÍGUEZ, P (2007): «El nuevo diseño de las competencias locales», Cuadernos Derecho Local XIII: 43.

RIVERO YSERN, J. L (2014). Manual de Derecho Local. Aranzadi. Navarra.

SÁNCHEZ DÍAZ, J. L (1980): "Competencia y autonomía municipal», Anales de la Universidad de Murcia XXXIV: 421436.

VELASCO CABALLERO, F (2014). Títulos competenciales y garantía constitucional de autonomía local en la Ley de Racionalización y sostenibilidad de la Administración Local, en La Reforma de 2013 del régimen local español (coord. Juan Alfonso Santamaría Pastor). Madrid, Fundación Democracia y Gobierno Local. Madrid.

VILLACORTA MANCEBO, L (2001): «Sobre el principio estructural de autonomía en la Constitución española y su desarrollo», Cuadernos constitucionales de la Cátedra Fadrique Furió Ceriol. XXXVI-XXXVII: 49-88. 